\title{
RESEARCH ON THE COMPARISON OF NON-STEROIDAL ANTI-INFLAMMATORY DRUGS (NSAID) AND OPIOIDS IN LOW BACK PAIN
}

\author{
Burak Katipoglu ${ }^{1}$, Eylem Kuday Kaykisiz ${ }^{2}$ \\ ${ }^{1}$ Ufuk Univerity Dr Ridvan Ege Research and Training Hospital, Ankara, Turkey \\ ${ }^{2}$ Bitlis State Hospital, Bitlis State Hospital Department of Emergency Medicine, 13000 Bitlis, Turkey
}

\begin{abstract}
INTRODUCTION: Opioids and Non-steroidal anti-inflammatory drugs (NSAID) are used to manage low back pain. However, it has been reported in some researches that opioids have fewer side effects than NSAID.
\end{abstract}

METHODS: Patient files of all the patients admitted to the emergency department of Ufuk University ethics committee on 23.03.2018 and applied with severe nontraumatic low back pain between 01.01.2015 and 01.01 .2016 were examined retrospectively. It was aimed to evaluate the efficacy of these two drugs in the treatment of pain by evaluating the responses of these patients with visual analogue scale scales.

RESULTS: A total of 138 patients among 911 patients experiencing low back pain were included in the study. 81 patients received $75 \mathrm{mg}$ of diclofenac sodium therapy alone, 57 patients received only Petidin hydrochloride treatment. 64 (46.4\%) of the patients were male and 74 (53.6\%) were female. It was found that there was no statistically significant correlation between pain scores of $75 \mathrm{mg}$ of diclofenac sodium imide treatment applied and Pethidine hydrochloride applied patient groups $(p>0.05)$. There was no statistically significant correlation between pain scores and genders of $75 \mathrm{mg}$ of diclofenac sodium imide treatment applied and Pethidine hydrochloride applied patient groups ( $p>0.05$ ). The difference between patients' referral scores and pain scores after 45 minutes $(75 \mathrm{mg}$ diclofenac sodium imide and petidine hydrochloride imide) were found to be statistically insignificant $(p>0.05)$. There was no statistically significant difference in the analyzed results of the efficacy of $75 \mathrm{mg}$ diclofenac sodium treatment related to gender ( $p>0.05)$. There was no statistically significant difference in the analyzed results of the efficacy of Pethidine hydrochloride treatment related to sex $(p>0.05)$.

CONCLUSIONS: Opioids have fewer side effects than NSAIDs in short period management of the pain, and they may be used for low back pain management in emergency services instead of NSAIDs.

KEY WORDS: opioid, NSAID, low back pain, pain management, emergency

Disaster Emerg Med J 2019; 4(1): 1-4

\section{INTRODUCTION}

Pain is one of the most common symptoms required for emergency service treatment. Low back pain is the most common musculoskeletal system disease [1]. Its prevalence was reported as $4.39 \%$ in a sys- tematic meta-analysis of 21 articles and 19 researches between 2000-2016 [2].

Individual pain experience varies depending on the current and past medical history, physical and emotional state, cognitional health, description of 
the pain, culture and environment. Pain is described as complex phenomena defined by physiologic, cultural and social-demographic factors [3].

The basic principle of effective pharmacologic pain management in emergency service is the selection of an agent suitable to pain level, having rapid analgesic activity outset, easy and safety to use. Pain scales must be used to evaluate the level of the pain. Aims of pain scales are defining seriousness level of pain, selecting proper analgesic agent type, its dosage and using properties. It is known that reporting of the pain by the patient is the most reliable indicator. In literature, the Visual Analog Scale (VAS) and Numeric Rating Scale (NRS), and both of them have high correlation [4].

Patients with acute pain in emergency departments are advised to provide appropriate analgesia according to the patient's pain severity. The first priority in Emergency care should be managing pain. Pain management should be initiated as soon as the patient first met and should be terminated by the application of the correct analgesic drug at the appropriate time. In the treatment of pain, the selection of the agent should be decided according to the severity and clinical condition of the patient. Non-steroidal anti-inflammatory drugs (NSAID) and oral opioids should be preferred in mild-to-moderate pain and parenteral opioids in severe pain [5].

The analgesic activity of opioids for acute pain is well established, but there have not been sufficient data on back pain. It is reported that opioids may be used for short-term treatment of severe pain in the guidelines of the National Institute of Health and Care Excellence (NICE) and the American College of Physicians and the American Pain Society (ACP/APS) [6] It is recommended that opioids should be used with caution in severe pain that can not be controlled by NSAIDs and acetaminophen [6]. However, the potential benefits and losses of opioid analgesics should be carefully compared before treatment begins.

In this study, we aimed to evaluate the efficacy of $75 \mathrm{mg}$ of diclofenac sodium, which is an opioid Pethidine hydrochloride and NSAID, in the treatment of patients with emergency nontraumatic low back pain.

\section{METHODS}

In the research, patient files of all patients admitted to the emergency department of Ufuk University ethics committee on 23.03.2018 and applied with severe nontraumatic low back pain between 01.01.2015 and 01.01.2016 were examined retrospectively.

This study was conducted in concordance with the World Medical Association Declaration of Helsinki "Ethical Principles for Medical Research Involving Human Subjects", (amended in October 2013). A consent form wasn't obtained from the patients due to the retrospective nature of the study. This study was approved by the ethics committee of Ufuk University.

Visual analogue scales numerically represented as 7 and above, with the exclusion criteria for patients aged 18-65 years; $100 \mathrm{mg}$ of pediatric alcoholic disease after exclusion of malignancy, chronic renal failure, diabetes mellitus, cardiovascular diseases, liver failure, hematological diseases, active infection, smoking, alcohol dependence, autoimmune disease, cerebrovascular events, pulmonary embolism, pregnancy, hydrochloride intramuscular and $75 \mathrm{mg}$ diclofenac sodium intramuscular only were included in the study. It was aimed to evaluate the efficacy of these two drugs in the treatment of pain by evaluating the responses of these patients with visual analogue scale scales. All these data were analyzed statistically using SPSS. A p-value $<0.05$ was considered as statistically significant.

\section{RESULTS}

In total, 22,680 patients between 01.01.2015 and 01.01.2016 were applied to our emergency service. Out of these patients 911 had a low back pain diagnosis. 315 patients were not able to obtain visual analogue scale file record before or after treatment. 253 patients had combined drug use for low back pain or use of a different NSAID and Opioid agent. 205 patients were excluded because ofthe exclusion criteria of the study. A total of 138 patients having the study criteria were included in the study with the complaint of nontraumatic low back pain. Eightyone patients received $75 \mathrm{mg}$ of diclofenac sodium therapy alone, 57 patients received only Petihdine hydrochloride treatment. 64 of the patients (46.4\%) were male and 74 were female (53.6\%).

In our study, nontraumatic low back pain and emergency pain at the time of admission were not statistically related to gender $(p>0.05)$. The physician's desire to choose drug or NSAID treatment was not associated with pain severity at the time of admission to the emergency department. There 
was no statistically significant correlation between pain scores of $75 \mathrm{mg}$ of diclofenac sodium imide treatment applied and Pethidine hydrochloride applied patient groups ( $p>0.05$ ) (Tab. 1). There was no statistically significant correlation between pain scores and genders of $75 \mathrm{mg}$ of diclofenac sodium imide treatment applied and Pethidine hydrochloride applied patient groups ( $p>0.05$ ) (Tab. 2).

The difference between patients' referral scores and pain scores after 45 minutes (75 mg diclofenac sodium imide and pethidine hydrochloride imide) were found to be statistically insignificant ( $p$ >0.05) (Tab. 3).

There was no statistically significant difference in the analyzed results of the efficacy of 75 of $\mathrm{mg}$ diclofenac sodium treatment related to gender
( $p>0.495)$. Similarly, there was no statistically significant difference in the analyzed results of the efficacy of Pethidine hydrochloride treatment related to sex (p: 0.974) (Tab. 4).

\section{DISCUSSION}

In a study conducted by Gottlieb et al., Opioid, myorelaxant, and placebo were given by oral route along with NSAID for patients with low back pain [7]. There was no difference in the treatments given for pain activity but there was a significant difference in the opioid group in terms of side effect. In a systematic review conducted by White et al it was evaluated that opioids are more effective than placebo in chronic low back pain when compared to NSAID [8].

Table 1. Relationship between gender and treatment regimens according to VAS values at emergency department admission

\begin{tabular}{|c|c|c|c|c|c|c|c|c|c|c|c|c|}
\hline & & \multicolumn{11}{|c|}{ Initial Pain Score } \\
\hline & & Mean & $\% 9$ & $5 \mathrm{Cl}$ & Median & SE & SD & Min & Max & $\% 25$ & $\% 75$ & $p$ \\
\hline \multirow[t]{2}{*}{ Sex } & Male $(n=64)$ & 8.34 & 8.07 & 8.62 & 8 & 0.139 & 1.116 & 7 & 10 & 7 & 9 & \multirow[t]{2}{*}{0.753} \\
\hline & Female $(n=74)$ & 8.28 & 8.03 & 8.54 & 8 & 0.128 & 1.104 & 7 & 10 & 7 & 9 & \\
\hline \multirow[t]{2}{*}{ Treatment } & $\begin{array}{l}\text { Diclofenac Soium } \\
(n=81)\end{array}$ & 8.26 & 8.02 & 8.5 & 8 & 0.123 & 1.104 & 7 & 10 & 7 & 9 & \multirow[t]{2}{*}{0.501} \\
\hline & $\begin{array}{l}\text { Petidin } \\
\text { hydrochloride }(n=57)\end{array}$ & 8.39 & 8.09 & 8.68 & 8 & 0.148 & 1.114 & 7 & 10 & 9 & 9 & \\
\hline
\end{tabular}

Table 2. Relationship between the VAS values of the patients and the genders according to the treatment regimens

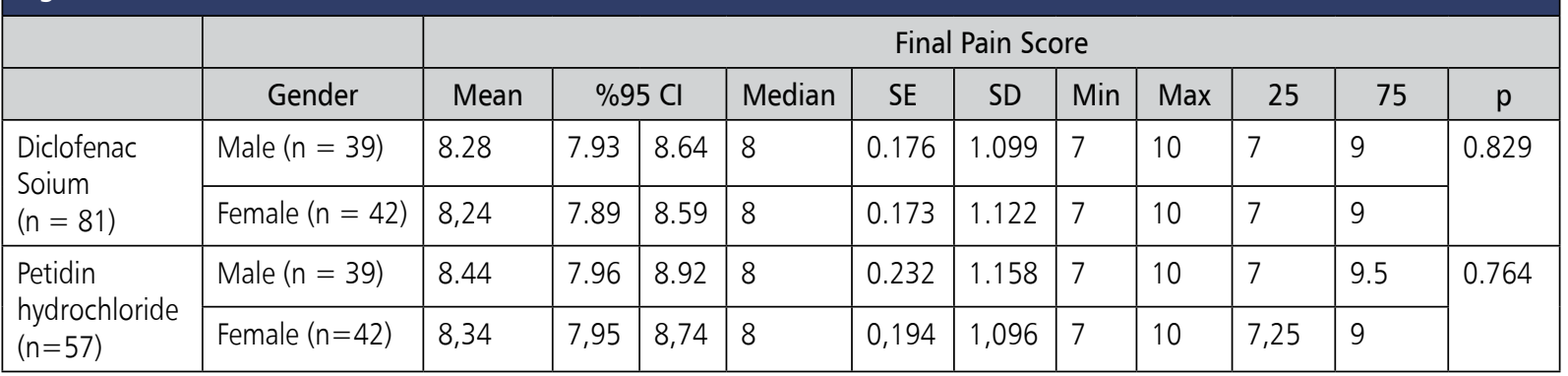

\begin{tabular}{|l|c|c|c|c|c|c|c|c|c|c|c|}
\hline & Table 3. Relationship between Diclofenac Sodium and Pethidine Hydrochloride Treatment Effectiveness \\
\hline & Mean & \multicolumn{7}{|c|}{ The Difference Between Pre-Treatment And Post-Treatment Pain Severity } \\
\hline & 5.86 & 5.55 & 6.16 & 6 & 0.152 & 1.376 & 3 & 9 & 5 & 7 & 0.857 \\
\hline $\begin{array}{l}\text { Diclofenac Soium } \\
(\mathrm{n}=81)\end{array}$ & 5.87 & 5.40 & 6.34 & 6 & 0.234 & 1.773 & 2 & 9 & 5 & 7 & \\
\hline $\begin{array}{l}\text { Petidin } \\
\text { hydrochloride }(\mathrm{n}=57)\end{array}$ & & & & & & & & & & & \\
\hline
\end{tabular}


Table 4. Relationship between treatment responses of patients and gender according to treatment regimens

\begin{tabular}{|c|c|c|c|c|c|c|c|c|c|c|c|c|}
\hline & & The Diff & ence & etwee & Pre-Treatn & ent Anc & ost-Tre & nent $P$ & n Sev & & & \\
\hline \multirow{3}{*}{$\begin{array}{l}\text { Diclofenac } \\
\text { Soium } \\
(n=81)\end{array}$} & Gender & Mean & \multicolumn{2}{|c|}{$\% 95 \mathrm{Cl}$} & Median & SE & SD & Min & Max & 25 & 75 & $p$ \\
\hline & Male $(n=39)$ & 6.00 & 5.57 & 6.42 & 6 & 0.211 & 1.317 & 4 & 9 & 5 & 7 & \multirow{2}{*}{0.495} \\
\hline & Female $(n=42)$ & 5.73 & 5.29 & 6.18 & 6 & 0.221 & 1.432 & 3 & 8 & 5 & 7 & \\
\hline \multirow{2}{*}{$\begin{array}{l}\text { Petidin } \\
\text { hydrochloride } \\
(n=57)\end{array}$} & Male $(n=39)$ & 5.84 & 5.14 & $6 ., 53$ & 6 & 0.335 & 1.675 & 2 & 8 & 4,5 & 7 & \multirow[t]{2}{*}{0.974} \\
\hline & Female $(n=42)$ & 5.90 & 5.23 & 6.58 & 6 & 0.331 & 1.872 & 2 & 9 & 5 & 7 & \\
\hline
\end{tabular}

Biylk et al. randomized 30 patients to $800 \mathrm{mg} /$ day of gabapentin $(n=55)$ and $75 \mathrm{mg} /$ day of diclofenac $(n=55)$ on 110 patients with chronic post-sternotomy chest pain and paresthesia (PCPP) with 3 months follow up. They reported that both gabapentin and diclofenac are effective in the treatment of chronic non-ischemic chest pain and paresthesia after sternotomy, without significant side effects. However, they found that gabapentin was superior to diclofenac and the effect lasted longer [9]. We think that the efficacy of pain in this study differs because of the use of drugs for a long time compared with our study.

Yeganeh Mogadama et al. found no statistically significant difference between groups of patients using gabapentin and diclofenac in a double-blind, placebo-controlled clinical trial of 90 patients for tonsillectomy pain management. They reported that both groups were effective in the treatment of pain compared with the placebo group. There was no statistically significant difference in drug side effects between the groups [10].

\section{CONCLUSION}

The physician's selection of drugs or NSAID treatment was not associated with pain severity at the time of admission to the emergency department. On the other hand, it was found that opioids have fewer side effects than NSAIDs in short period management of the pain. Thus, opioids may be used for low back pain management in emergency services instead of NSAIDs.

\section{REFERENCES}

1. Rizzardo A, Miceli L, Bednarova R, et al. Low-back pain at the emergency department: still not being managed? Ther Clin Risk Manag.
2016; 12: 183-187, doi: 10.2147/TCRM.S91898, indexed in Pubmed: 26929631.

2. Edwards J, Hayden J, Asbridge $M$, et al. Prevalence of low back pain in emergency settings: a systematic review and meta-analysis. BMC Musculoskelet Disord. 2017; 18(1): 143, doi: 10.1186/s12891-0171511-7, indexed in Pubmed: 28376873.

3. Baharuddin KA, Mohamad N, Nik Abdul Rahman NH, et al. Assessing Patient Pain Scores in the Emergency Department. Malays J Med Sci. 2010; 17(1): 17-22.

4. Singer A, Kowalska A, Thode H. Ability of Patients to Accurately Recall the Severity of Acute Painful Events. Academic Emergency Medicine. 2001; 8(3): 292-295, doi: 10.1111/j.1553-2712.2001.tb01310.x.

5. Karcıoğlu 0̈. Management of pain and practice of analgesia in the emergency setting. Turkiye Aile Hekimligi Dergisi. 2010; 14(2): 53-63, doi: 10.2399/tahd.10.053.

6. Chou R, Qaseem A, Snow V, et al. Diagnosis and Treatment of Low Back Pain: A Joint Clinical Practice Guideline from the American College of Physicians and the American Pain Society. Annals of Internal Medicine. 2007; 147(7): 478, doi: 10.7326/0003-4819-1477-200710020-00006.

7. Gottlieb M, Njie A. Comparison of naproxen with cyclobenzaprine, oxycodone-acetaminophen, and placebo for the treatment of acute low back pain. CJEM. 2016; 18(6): 491-494, doi: 10.1017/cem.2016.370, indexed in Pubmed: 27640607.

8. White AP, Arnold PM, Norvell DC, et al. Pharmacologic management of chronic low back pain: synthesis of the evidence. Spine (Phila Pa 1976). 2011; 36(21 Suppl): S131-S143, doi: 10.1097/BRS.0b013e31822f178f, indexed in Pubmed: 21952185.

9. Biyik I, Gülcüler M, Karabiga $M$, et al. Efficacy of gabapentin versus diclofenac in the treatment of chest pain and paresthesia in patients with sternotomy. Anadolu Kardiyol Derg. 2009; 9(5): 390-396, indexed in Pubmed: 19819790.

10. Yeganeh Mogadam A, Fazel MR, Parviz S. Comparison of analgesic effect between gabapentin and diclofenac on post-operative pain in patients undergoing tonsillectomy. Arch Trauma Res. 2012; 1(3): 108-111, doi: 10.5812/atr.7931, indexed in Pubmed: 24396757. 